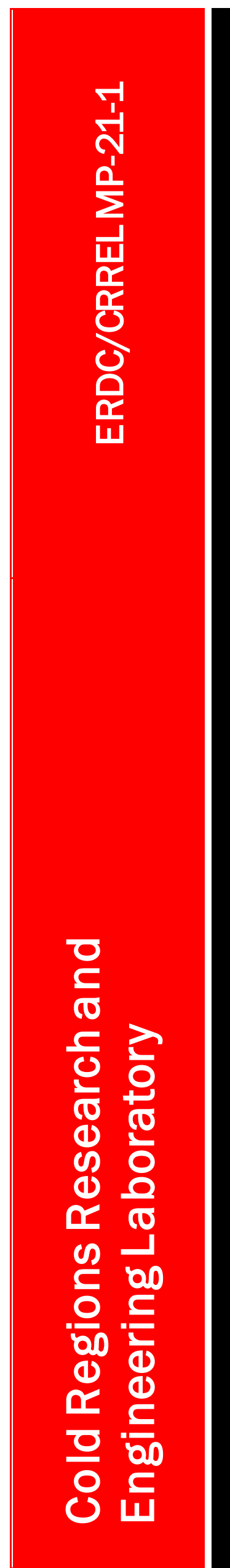

Scale Invariance of Albedo-Based Wind Friction Velocity

Nancy P. Ziegler, Nicholas P. Webb, Adrian Chappell, and April 2021 
The U.S. Army Engineer Research and Development Center (ERDC) solves the nation's toughest engineering and environmental challenges. ERDC develops innovative solutions in civil and military engineering, geospatial sciences, water resources, and environmental sciences for the Army, the Department of Defense, civilian agencies, and our nation's public good. Find out more at www.erdc.usace.army.mil.

To search for other technical reports published by ERDC, visit the ERDC onlinelibrary at https://erdclibrary.on.worldcat.org/discovery. 


\title{
Scale Invariance of Albedo-Based Wind Friction Velocity
}

\author{
Nancy P. Ziegler and Sandra L. LeGrand \\ Cold Regions Research Laboratory \\ U.S. Army Engineer Research and Development Center \\ 72 Lyme Road \\ Hanover, NH 03755 \\ Nicholas P. Webb \\ USDA-ARS \\ Jornada Experimental Range \\ Las Cruces, NM 88003 \\ Adrian Chappell \\ School of Earth and Ocean Sciences \\ Cardiff University \\ Cardiff CF10 3XQ, UK
}

Final report

Approved for public release; distribution is unlimited.

\author{
Prepared for U.S. Army Corps of Engineers \\ Washington, DC 20314 \\ Under Project Number 480351, PE 611102AB200
}




\section{Abstract}

Obtaining reliable estimates of aerodynamic roughness is necessary to interpret and accurately predict aeolian sediment transport dynamics. However, inherent uncertainties in field measurements and models of surface aerodynamic properties continue to undermine aeolian research, monitoring, and dust modeling. A new relation between aerodynamic shelter and land surface shadow has been established at the wind tunnel scale, enabling the potential for estimates of wind erosion and dust emission to be obtained across scales from albedo data. Here, we compare estimates of wind friction velocity $\left(u^{*}\right)$ derived from traditional methods (wind speed profiles) with those derived from the albedo model at two separate scales using bare soil patch (via net radiometers) and landscape (via MODIS 500 m) datasets. Results show that profile-derived estimates of $u^{*}$ are highly variable in anisotropic surface roughness due to changes in wind direction and fetch. Wind speed profiles poorly estimate soil surface (bed) wind friction velocities necessary for aeolian sediment transport research and modeling. Albedo-based estimates of $u^{*}$ at both scales have small variability because the estimate is integrated over a defined, fixed area and resolves the partition of wind momentum between roughness elements and the soil surface. We demonstrate that the wind tunnel-based calibration of albedo for predicting wind friction velocities at the soil surface $\left(u s^{*}\right)$ is applicable across scales. The albedo-based approach enables consistent and reliable drag partition correction across scales for model and field estimates of $u s^{*}$ necessary for wind erosion and dust emission modeling.

DISCLAIMER: The contents of this report are not to be used for advertising, publication, or promotional purposes. Citation of trade names does not constitute an official endorsement or approval of the use of such commercial products. All product names and trademarks cited are the property of their respective owners. The findings of this report are not to be construed as an official Department of the Army position unless so designated by other authorized documents. 


\section{Preface}

This study was conducted for the U.S. Army Corps of Engineers under Project number 480351, PE 611102AB200. The Technical monitor was Mr. Austin Davis.

The work was performed by the Biogeochemical Sciences Branch and Terrestrial and Cryospheric Sciences Branch of the Research and Engineering Division, U.S. Army Engineer Research and Development Center, Cold Regions Research and Engineering Laboratory (ERDC-CRREL). At the time of publication, Dr. Steven Peckham was Acting Branch Chief; Dr. George Calfas was Acting Division Chief; and Ms. Pamela Kinnebrew was the Technical Director for Military Engineering. The Deputy Director for ERDC-CRREL was Mr. David Ringelberg and the Director was Dr. Joseph Corriveau.

This paper was originally published in the Journal of Geophysical Research: Atmospheres on 26 July 2020.

The Commander of ERDC was COL Teresa A. Schlosser and the Director was Dr. David W. Pittman. 


\section{Introduction}

Wind erosion and dust emission exhibit large spatiotemporal variability in response to land surface-atmosphere interactions within the planetary boundary layer (Bergametti \& Gillette, 2010; Sweeney et al., 2011). These interactions are controlled by soil properties, atmospheric turbulence, and drag partitioning between roughness elements at different scales that affect the aerodynamic roughness length ( $z o$ ), total wind friction velocity $\left(u^{*}\right)$, and wind friction velocity at the soil surface or bed $\left(u s^{*}\right)$ (Raupach et al., 1993). Obtaining reliable estimates of $z o$ and $u_{s^{*}}$ is necessary to interpret and accurately predict sediment transport dynamics. However, inherent variability in single point-based (i.e., wind speed profile) field measurements of these aerodynamic properties is not captured in dust models and continues to impact the accuracy of areal wind erosion and dust emission estimates (Dupont et al., 2018).

Field measurements of $z o$ and $u^{*}$ derived from wind speed profiles and sonic anemometry are influenced by roughness at different scales responding to wind speed and direction with respect to upwind surface roughness across often undefined heterogeneous fetch (Zobeck et al., 2003). Large variability in wind speed profile-derived $z o$ has been documented previously (e.g., Chappell et al., 2010; Gillette et al., 2006; King et al., 2006; Nield et al., 2013) and is informative of the influence of surface roughness on $u^{*}$ at the measurement location (André \& Blondin, 1986; Dupont et al., 2018). However, variability in $z o$ and $u^{*}$ detected from a single wind speed profile incompletely samples, and therefore inaccurately estimates, the total variability in the properties across an area of landscape. Measuring wind speed profile-derived $z o$ at multiple locations within a land cover type (or experimental site) would produce different values of $z o$ and $u^{*}$ due to differences in wind momentum reduction and sheltering by heterogeneous roughness. Anisotopic aerodynamic roughness influences the magnitude of $z o$ and its variability across land cover types (Gillies et al., 2007; King et al., 2006). Inadequately estimating $z o$ and $u^{*}$ is a major source of uncertainty in dust models dependent on these properties (Raupach \& Lu, 2004). Adequately measuring the spatiotemporal variability of $z o$ to parameterize areal dust models would require multiple samples in space (Chappell et al., 2003; Sterk \& Stein, 1997; Chappell et al., 2003). Typi- 
cally, measurements of zo made frequently over time from a single meteorological tower are used to represent temporal variability, and effects of roughness in different directions. Consequently, individual wind speed profiles have limited utility for understanding how $u^{*}$ influences aeolian transport at scales other than a single location in space, and particularly in parameterizing regional and global dust models (e.g., Marticorena and Bergametti, 1995). Current dust models that rely on look-up tables of $z o$ derived from field measurements or boundary-layer models inadequately represent the often large spatial variability in roughness (Raupach and $\mathrm{Lu}$, 2004). This is because of the fundamental feedback between roughness and wind speed represented by aerodynamic roughness: as wind speed increases the relative influence of the (vertical) roughness is reduced. Large spatial variability in surface aerodynamic properties and aeolian sediment transport necessitate more sophisticated measurement approaches that can support field research and improve the accuracy of areal wind erosion and dust emission models (Webb et al., 2019; 2020).

Further compounding the variability-driven uncertainty in estimating areal $z_{o}$ and $u^{*}$, wind speed profiles do not estimate the momentum partition between roughness elements and the soil surface (Raupach, 1992). Estimates of $u^{*}$ from wind speed profiles above a canopy of roughness elements (vegetation or rocks) represent the total wind friction velocity $\left(u^{*}\right)$ and not the soil surface (bed) friction velocity $\left(u s^{*}\right)$ required to understand and predict sediment transport. Drag partition schemes have enabled estimates of shear stress partitioning and $u s^{*}$ across spatial scales (e.g., plot, 100 m2, to landscape, 1000 m2 scales, Raupach et al., 1993; Marticorena \& Bergametti, 1995). However, areal applications of these schemes rely on estimates of $z o$ that include unexplained variability (uncertainty) in field measurements, or approximations based on the lateral cover of roughness $(\lambda)$ which underestimate surface sheltering (Chappell \& Webb, 2016) and inadequately represents spatial heterogeneity in the momentum partition (Webb et al., 2014a; Chappell \& Webb, 2016). Uncertainties in shear stress partitioning propagate through models and contribute to the inaccuracy of current dust models (e.g., Shao et al., 2011; LeGrand et al., 2019; Webb et al., 2020). Approaches that resolve the spatial distribution of $u_{s^{*}}$ have been shown to be more accurate than models based on $z o$ and $\lambda$ (Okin, 2008; $\mathrm{Li}$ et al., 2013). However, applications that rely on field measurements of vegetation spatial distributions have so far been limited by data availability (e.g., Vest et al., 2013; Webb et al., 2014b). The generality of drag partition 
schemes across spatial scales (e.g., $10 \mathrm{~m}^{2}$ to $10^{5} \mathrm{~m}^{2}$ ) and scales of roughness (e.g., $\mathrm{mm}$ to 10's of $\mathrm{m}$ ) remains largely untested. Difficulties with parameterization and insensitivity to roughness heterogeneity suggest that existing schemes do not scale linearly in space (Raupach \& Lu, 2004). Reducing both measurement and dust model uncertainties requires methods to estimate the areal shear stress partition and $u s^{*}$ that are sensitive to roughness heterogeneity and are generalizable across spatial extents and scales of roughness (Webb et al., 2014a; Chappell and Webb, 2016).

Satellite remote sensing provides the ability to produce area-weighted or integrated estimates of land surface characteristics across pixels (e.g., 500 x $500 \mathrm{~m}$ ). Approaches tested to resolve areal $z o$ and $u_{s^{*}}$ include radar backscatter coefficients (Greeley et al., 1991; Greeley et al., 1997; Marticorena et al., 2004; Marticorena et al., 2006), surface shadowing (Chappell \& Heritage, 2007; Chappell et al., 2010; Cho et al., 2012), and sensor bidirectional reflectance distribution function (BRDF) parameters (Xing et al., 2018). Using data from wind tunnel experiments, Chappell and Webb (2016) showed that aerodynamic sheltering can be approximated from land surface albedo normalized to remove surface spectral effects. Using the BRDF, the MODIS albedo data are integrated across viewing angles for a single illumination angle (solar noon), producing an areal shadow estimate. Using wind speed at $10 \mathrm{~m}$ to approximate the freestream wind speed $\left(U_{f}\right)$, this albedo-based approach can predict the partition of $u^{*}$ between roughness elements $\left(u r^{*}\right)$ and $u_{s^{*}}$ integrated over an area defined by the sensor (radiometer) field-of-view or satellite sensor (e.g. MODIS) pixel size. Although established at the scale of the wind tunnel, the approach is similar to all other wind tunnel aerodynamic extrapolations (cf. Raupach et al., 1993) and hypothesized to estimate area-integrated $u^{*}$ and $u s^{*}$ across scales of roughness orders of magnitude (i.e., $\mathrm{mm}$ to 10's of $\mathrm{m}$ ) larger. While these area-integrated estimates of $u^{*}$ and $u_{s^{*}}$ are omnidirectional, they incorporate directional effects of heterogenous roughness over a defined area (sensor field-of-view) and so could reduce the unexplained variation (uncertainty) arising from using single point estimates of $u^{*}$ from wind speed profiles to understand and model areal sediment transport.

The purpose of this study was to conduct the first field test of the albedo model against independent measurements of $u^{*}$ derived from wind speed profiles. Our objectives were to: (1) derive areal estimates of $u^{*}$ and $u s^{*}$ at different spatial scales using net radiometer and MODIS albedo data; (2) compare those areal estimates with estimates of $u^{*}$ derived from wind 
speed profiles from a single tower across land cover types; and (3) compare independent measurements of $u^{*}$ and surface albedo across land cover types with measurements of $u^{*}$ and $u_{s^{*}}$ underpinning the albedo model for different configurations of small-scale roughness elements obtained in the wind tunnel experiments of Marshall (1971). These comparisons enabled us to identify that the albedo-based model of Chappell and Webb (2016) produces direct estimates of $u^{*}$ and $u s^{*}$ that are robust across scales of roughness. 


\section{Methods}

\subsection{Site description}

We measured wind speed profile data from two study sites at the US Department of Agriculture - Agricultural Research Service (USDA-ARS) Jornada Experimental Range (JER) in southern New Mexico (Webb et al., 2016a) and ten National Wind Erosion Research Network (NWERN) sites (Webb et al., 2016b). The two JER sites included a playa site located on a Reagan sandy clay loam soil (Bulloch and Neher, 1980) with moderatelystrong physical crusting (Site 3 in Webb et al., 2016a), and an open shrubland site on a Harrisburg sandy loam soil (Bulloch and Neher, 1980) with weak physical crusting that is easily abraded under saltation bombardment (Site 4 in Webb et al., 2016a). The playa site is centered on a $\sim 2$ ha playa with sparse dropseed (Sporobolus R. Br.) and creosote bush (Larrea tridentata). The open shrubland site (herein JER Harrisburg site) is dominated by honey mesquite (Prosopis glandulosa Torr.), soaptree yucca (Yucca elata), and purple threeawn (Aristida purpurea Nutt.). The ten NWERN sites include those at the Jornada (open shrubland), San Luis Valley, CO (open shrubland), Heart Rock Ranch, ID (closed shrubland), Holloman Air Force Base, NM (grassland), Moab, UT (grassland), Central Plains Experimental Range, CO (grassland), Big Spring, TX (conventional tillage cropland), Pullman, WA (conventional tillage cropland), El Reno, OK (no tillage cropland), and Mandan, ND (no tillage cropland). Detailed biophysical characteristics for the network sites are provided in Webb et al. (2016b).

\subsection{Instrumentation}

All study sites were equipped with a meteorological tower measuring the vertical wind speed profile. The JER playa and Harrisburg open shrubland sites were both equipped with a central $5.0 \mathrm{~m}$ meteorological tower with RM Young 3101 cup anemometers at heights of $0.7 \mathrm{~m}, 1.4 \mathrm{~m}$ and $2.4 \mathrm{~m}$ above ground level, and one RM Young 3002 anemometer and wind vane at $4.8 \mathrm{~m}$ height. Temperature sensors (model 107-L) were mounted at 2.0 $\mathrm{m}$ and $4.0 \mathrm{~m}$ above ground level. A Sensit (model H14-LIN) saltation mass flux sensor, used to measure saltation particle counts and duration, was mounted with sensor surface $0.05 \mathrm{~m}$ above ground level and approximately 3.0 $\mathrm{m}$ from the meteorological towers. Kipp and Zonen CNR1 fourcomponent net radiometers were mounted $\sim 6 \mathrm{~m}$ west-southwest of the 
meteorological towers (aligned with the dominant wind direction), positioned $1.0 \mathrm{~m}$ above the ground, giving a measurement area of $314.16 \mathrm{~m}^{2}$. The radiometers measured incoming and outgoing solar radiation used to estimate albedo, the ratio of the incoming radiation (upper) to outgoing radiation (lower pyranometer) measurements, integrated across the range 305-2800 nm.

The NWERN sites were equipped with $10 \mathrm{~m}$ meteorological towers with five RM Young 3101 cup anemometers at heights of $0.5 \mathrm{~m}, 1.0 \mathrm{~m}, 1.5 \mathrm{~m}$, $2.5 \mathrm{~m}$, and $5 \mathrm{~m}$ above ground level, one RM Young 3002 anemometer and wind vane mounted at $10 \mathrm{~m}$, temperature sensors (model 107-L) mounted at 2.0 m and $10 \mathrm{~m}$, and a Rotronic HygroClip2 $\mathrm{HC}_{2} \mathrm{~S}_{3}-\mathrm{L}$ air temperature/relative humidity probe mounted at $4.0 \mathrm{~m}$. Sensit (model H14-LIN) saltation mass flux sensors were mounted with sensor surface $0.05 \mathrm{~m}$ above ground level and approximately $3 \mathrm{~m}$ from the meteorological towers. Meteorological measurements of the vertical wind speed profile, wind direction and temperature at all sites were sampled at 1 second and logged at a 60 second frequency on Campbell Scientific CR100o data loggers.

\subsection{Profile estimates of aerodynamic roughness length and wind friction velocity}

Wind speed profile data were used to estimate the aerodynamic roughness length $(z o)$ for each site following the Prandtl-von Kármán logarithmic velocity profile law:

$$
u_{*}=\frac{k U_{h}}{\ln \left(\frac{h}{z_{0}}\right)}
$$

where $U_{h}$ is the wind speed $\left(\mathrm{m} \mathrm{s}^{-1}\right)$ at height $h(\mathrm{~m}), u^{*}$ is the wind friction velocity $\left(\mathrm{m} \mathrm{s}^{-1}\right)$ and $k$ is von Kármán's constant (o.4). In this study we used $U_{h}$ (where $h$ is the height of the highest anemometer) to approximate $U_{f}$ (freestream wind speed). Wind speed data were resampled to 15 minute averages and estimates of $z o$ and $u^{*}$ were obtained following the linear regression approach of Zobeck et al. (2003):

$$
U_{h}=m \cdot \ln (h)+c,
$$

where $u_{*}=m k$ and $z_{0}=e^{-c / m}$. To ensure the wind speed profiles closely approximated a logarithmic profile, we applied criteria to select data with wind speeds at all heights $\left(U_{h}\right)>2 \mathrm{~ms}^{-1}$, remove values if the fit of the vertical wind speed data to Eq. 2 as defined by the correlation coefficient $\mathrm{r}^{2}<$ 
0.97 , and remove values for which differences in temperature $\Delta \mathrm{T}_{2 \mathrm{~m}-4 \mathrm{~m}}>$ $0.5^{\circ}$ at JER sites and $\Delta \mathrm{T}_{2 \mathrm{~m}-10 \mathrm{~m}}>0.5^{\circ}$ at NWERN sites, indicating atmospheric instability. Any time periods with $>15$ seconds saltation (as measured by a Sensit) were removed to eliminate the influence of saltationinduced changes to measured zo. A wind direction filter was implemented to avoid obstruction effects on the wind velocity profiles; data within $\pm 20^{\circ}$ and $\pm 10^{\circ}$ of the meteorological towers relative to the anemometers were removed at the JER and NWERN sites, respectively. The Central Plains Experimental Range (CPER) NWERN site data were also filtered within $\pm 20^{\circ}$ due to orientation of the anemometers on that tower relative to other sensors. We did not estimate the zero plane displacement height, $d$, due to uncertainties in its estimation over sparse, patchy vegetation that does not behave as a single unit (Wiggs et al., 1996). From the remaining data, daily mean $z o$ and $u^{*}$ were calculated from the 15 -minute estimates for comparison with radiometer and MODIS-derived wind friction velocities. We note that these are not complete daily means because they were calculated from the filtered data. To remove the effect of wind speed, the $u^{*}$ were normalized by $U_{h}$, where $U_{h}$ approximates $U_{f}$, by the wind speed measured from the highest anemometer at each site $(4.8 \mathrm{~m}$ at the JER sites and $10 \mathrm{~m}$ at the NWERN sites). Limited by the meteorological tower setup at the JER sites, the use of $4.8 \mathrm{~m}$ to approximate $U_{h}$ likely underestimates the freestream wind speed, $U_{f}$. Therefore, the $U_{h}$ was likely still influenced by surface roughness. We also recognize that the differences in anemometer heights in the normalization would affect direct comparison across the sites, so we did not seek to make direct comparisons among the JER and NWERN sites. To investigate the variability of $z o$ by wind direction, we calculated the standardized $z o$ anomalies by subtracting the annual mean $z o$ from each daily value and then dividing by the standard deviation.

\subsection{Radiometer-derived estimates of wind friction velocity}

We measured net radiation of the bare (unvegetated) soil surface (bed) albedo to estimate $u^{*} / U_{h}$ and $u_{s^{*}} / U_{h}$ adjacent to the meteorological towers following Chappell and Webb (2016):

$$
\begin{aligned}
& \frac{u *}{U_{h}}=0.0497\left(1-\exp \frac{-\omega_{n s}^{1.326}}{0.0027}\right)+0.038, \text { and } \\
& \frac{u_{s *}}{U_{h}}=0.0311\left(\exp \frac{-\omega_{n s^{1.131}}}{0.016}\right)+0.007
\end{aligned}
$$


where $\omega_{n s}$ is the rescaled, normalized albedo (Eq. 6; explained below). The CNR1 net radiometers have a $180^{\circ}$ field of view with a sensitivity that follows a cosine response, resulting in an unstable albedo signal at large solar illumination angles (Kipp \& Zonen, 2002). To account for this instability, we used albedo measurements collected at the daily minimum solar zenith angle $\left(\theta<36^{\circ}\right)$ (following Michalsky \& Hodges, 2013; Weiser et al., 2017). The net radiometer measurements were influenced by the solar illumination zenith angle $(\theta)$, soil moisture, soil mineralogy, and shadow due to roughness which all influence the spectral reflectance of the surface. To remove soil spectral reflectance effects on albedo and estimate the proportion of shadow, we followed Chappell et al. (2018) and calculated a normalized albedo $\left(\omega_{n}\right)$ by dividing the complement of the albedo at the daily minimum solar zenith angle $(\omega \mathrm{d}$.min) by the surface reflectance $(R)$ obtained for each site from $30 \mathrm{~m}$ Landsat 8 surface reflectance (Vermote et al., 2016):

Figure 1. Illustration of measurement systems for wind speed profiles, CNR1 net radiometer and MODIS satellite-based land surface albedo over the Jornada Experimental Range (JER) study sites.

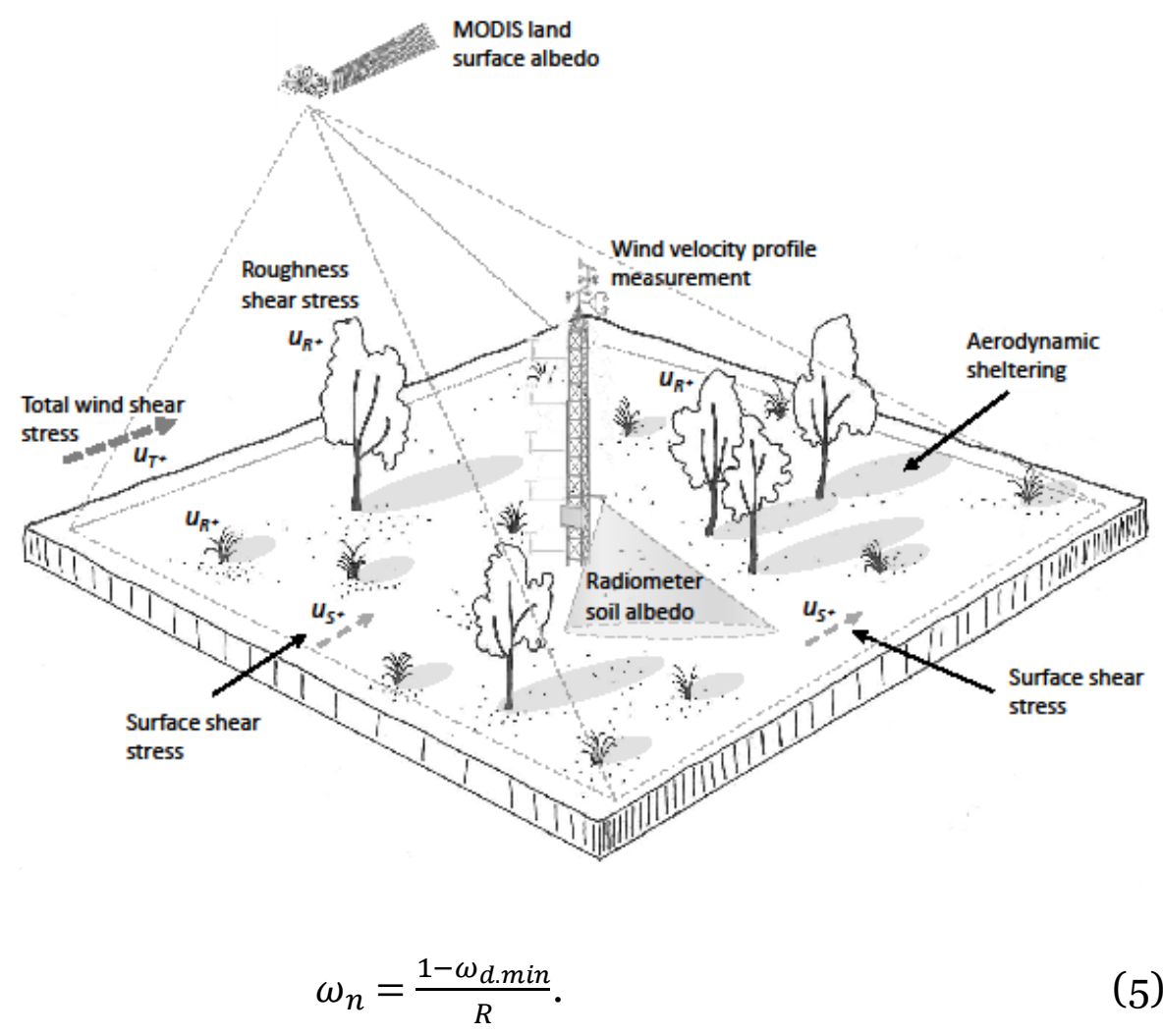


We then rescaled the normalized albedo $\left(\omega_{n}\right)$ from the field measurements to those of the wind tunnel range $a=0.0001$ to $b=0.1$, producing $\omega n s$ :

$$
\omega_{n s}=\frac{(a-b)\left(\omega_{n}-\omega_{n \cdot \max }\right)}{\left(\omega_{n . \min }-\omega_{n . \max }\right)}+b,
$$

where the minimum rescaling value of the normalized albedo, $\omega_{n \text { min }}=0$, and the maximum rescaling value, $\omega_{n \cdot \max }=1500$. Using the albedo at the daily minimum solar zenith angle resulted in single daily estimates of $u^{*} / U_{h}$ and $u_{s^{*}} / U_{h}$. These were filtered to remove days for which saltation was occurring (as measured by a Sensit) at the time the daily minimum solar zenith was measured. Data were also filtered to remove any minute in which rain or cloud cover was recorded. For the remaining data we assumed that, as roughness did not change (as rainfall and saltation were removed), measurements sufficiently characterized the surface roughness in the radiometer field-of-view over the course of a day. We estimated $u^{*} / U_{h}$ and $u_{s^{*}} / U_{h}$ daily for the period 1 April 2018 to 31 September 2018.

\subsection{MODIS-derived estimates of wind friction velocity}

To obtain large area estimates of $u^{*} / U_{h}$ (Eq. 3) and $u_{s^{*}} / U_{h}$ (Eq. 4) incorporating surrounding vegetation effects, we calculated daily mean values using the $500 \mathrm{~m}$ MODIS albedo product (Collection 6, MCD43A1) following Chappell and Webb (2016). Here, we estimated the surface shadowing (sheltering) using the complement of the directional albedo $1-\omega \operatorname{dir}(\theta, v)$ normalized by the MODIS isotropic parameter $f_{i s o}$ :

$$
\omega_{n . m o d i s}=\frac{1-\omega_{\operatorname{dir}}(\theta, v)}{f_{i s o}(v)}=\frac{1-\omega_{\operatorname{dir}}\left(0^{\circ}\right)}{f_{i s o}},
$$

where $\omega \operatorname{dir}(\theta, v)$ is a function of solar zenith angle $(\theta)$, spectra-dependent $(v)$ direct-beam albedo, taken as the 'black-sky' albedo for MODIS band 1 $(620-670 \mathrm{~nm})$, and $f_{\text {iso }}$ is an isotropic weighting parameter from the MODIS BRDF model that represents the spectral contribution of the surface. We extracted daily at- nadir $\omega \operatorname{dir}\left(\mathrm{O}^{\circ}\right)$ for the period 1 April 2018 to 31 September 2018 for the 500 m pixel within the JER playa, JER Harrisburg open shrubland, and ten NWERN sites. We used Equation (6) to rescale

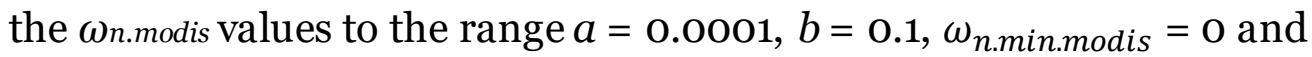
$\omega_{\text {n.max.modis }}=35$, and Eqs. (3) and (4) to estimate $u^{*} / U_{h}$ and $u_{s^{*}} / U_{h}$. The $\omega_{n \text {.max }}$ for the radiometer and $\omega_{n \text { max.modis values were unique to the sensors }}$ due to different spectral ranges over which the albedo was calculated. The 
data were not filtered for saltation because the MODIS BRDF daily product is calculated from data collected over a 16-day period and inverts multi-date surface reflectance observations (Schaaf et al., 2002).

Figure 2. Images of the Jornada Experimental Range (JER) playa and Harrisburg open shrubland sites with MODIS 500-m pixels over the field site boundaries (red boxes), close-up images of the sites and CNR1 net radiometer fields of view within the sites (blue boxes). At the playa site, surrounding vegetated sand ridges and grass patches (dark gray) are visible in the overhead imagery.

JER Playa
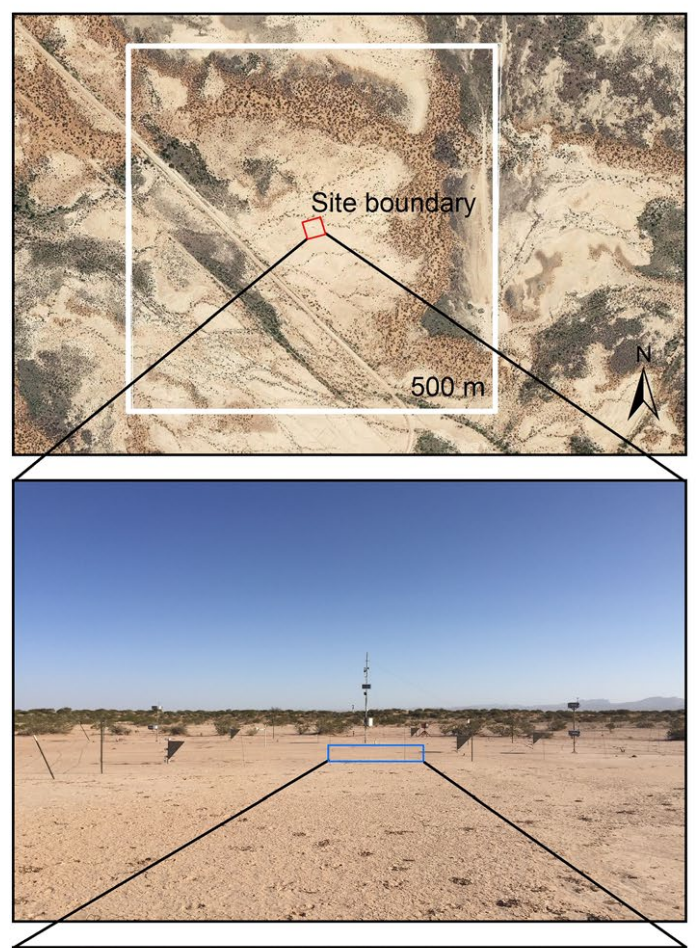

Surface within CNR1 radiometer field of view
JER Harrisburg open shrubland
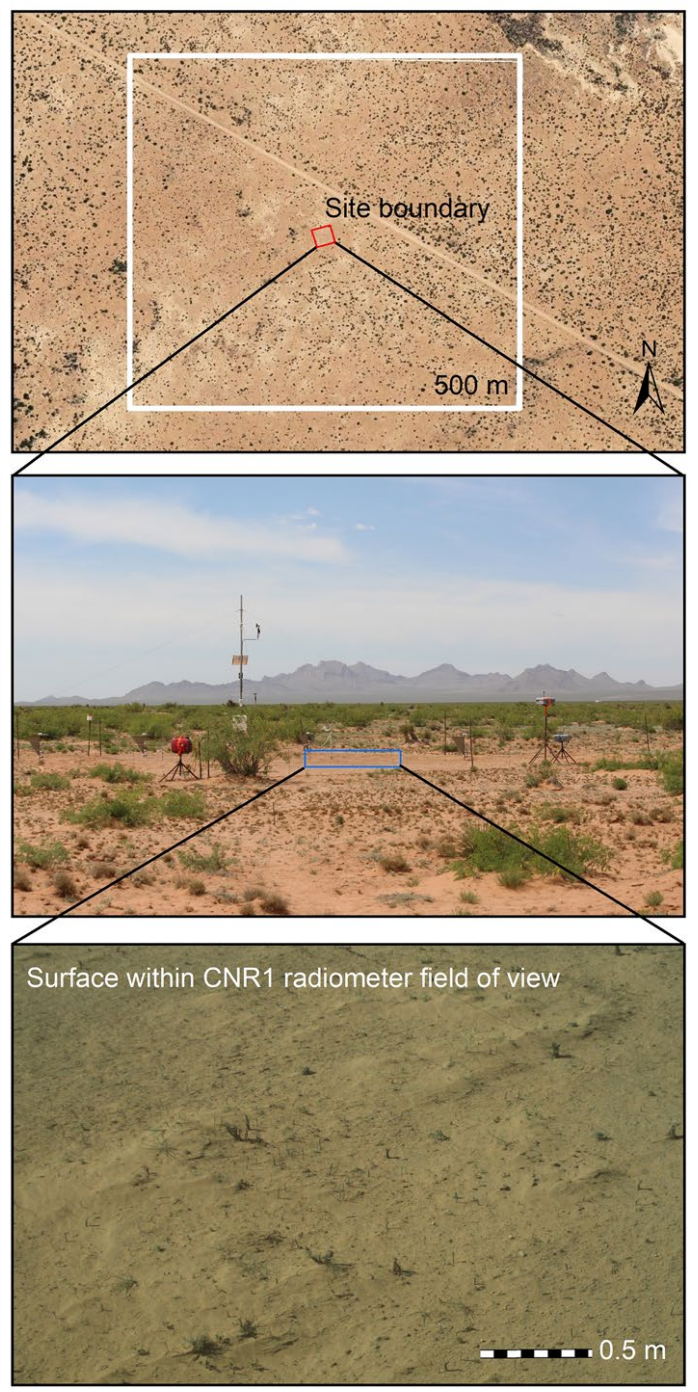

To compare estimates of $u^{*} / U_{h}$ derived from the wind speed profiles, radiometers, and MODIS data, we define the following nomenclature: $u^{*}$ profile $/ U_{h}$ (wind speed profile-derived estimates), $u^{*}{ }^{*} a d / U_{h}$ and $u_{s^{*}} \mathrm{rad} / U_{h}$ (radiometer-derived estimates), and $u^{*}$ modis/Uh and $u_{s}{ }^{*}$ modis/ $U_{h}$ (MODIS- 
derived estimates). To quantify the variability for each of the three estimates, we calculated their mean, median, standard deviation of the mean, and the coefficient of variance (CV; standard deviation of the mean divided by the mean) at each of the JER sites. At the NWERN sites, we calculated the mean, median, standard deviation, and CV of $u^{*} / U_{h}$ and $u_{s^{*}} / U_{h}$ obtained from the MODIS model and $u^{*} / U_{h}$ from the wind speed profiles. To assess the variability in aerodynamic roughness across the land cover types, we calculated the annual and seasonal mean, median, variance and $\mathrm{CV}$ of $z o$ at each site. We also calculated the standardized $z o$ anomalies at each site. Finally, we plotted the estimates of $u^{*}$ profile/ $U_{h}$ against rescaled normalized albedo $(\omega n s)$ from the NWERN sites with Marshall's (1971) wind tunnel measurements of surface shear stress $\tau\left(\mathrm{N} \mathrm{m}^{-2}\right)$, converted to $u^{*}=\sqrt{\tau / \rho_{a}}$ where $\rho_{a}$ is the air density, across different roughness configurations to test the generality of the Chappell and Webb (2016) model across scales of roughness.

Table 1. Summary of wind speed profile-based, radiometer-based, and MODIS-based shear stress statistics ( $C V=$ Coeffient of Variance) from the JER Playa and Harrisburg sites.

\begin{tabular}{|c|c|c|c|c|c|c|}
\hline Site & IGBP land cover class & Friction velocity & Mean & Median & Standard deviation & $\mathrm{CV}(\%)$ \\
\hline \multirow[t]{5}{*}{ JER playa } & \multirow[t]{5}{*}{ Playa } & $u_{* \text { profite }} / U_{h}$ & 0.0399 & 0.0392 & 0.0056 & 14.021 \\
\hline & & $u_{*_{r a d}} / U_{h}$ & 0.0382 & 0.0382 & $8.75 \times 10^{-6}$ & 0.0229 \\
\hline & & $u_{*}$ modis $/ U_{h}$ & 0.0596 & 0.0586 & 0.0023 & 3.9304 \\
\hline & & $u_{s * r a d} / U_{h}$ & 0.0380 & 0.0380 & $4.20 \times 10^{-6}$ & 0.0111 \\
\hline & & $u_{s} s_{\text {modis }} / U_{h}$ & 0.0312 & 0.0316 & 0.0008 & 2.4460 \\
\hline \multirow[t]{5}{*}{ JER Harrisburg } & \multirow[t]{5}{*}{ Open shrubland } & $u_{* \text { profite }} / U_{h}$ & 0.0595 & 0.0599 & 0.0060 & 10.036 \\
\hline & & $u_{*} *_{r a d} / U_{h}$ & 0.0382 & 0.0382 & $1.10 \times 10^{-5}$ & 0.0287 \\
\hline & & $u *_{\text {modis }} / U_{h}$ & 0.0569 & 0.0570 & 0.0008 & 1.3698 \\
\hline & & $u_{s}{ }^{*} \mathrm{rad} / U_{h}$ & 0.0380 & 0.0380 & $5.17 \times 10^{-6}$ & 0.0136 \\
\hline & & $u_{s^{*} \text { modis }} / U_{h}$ & 0.0321 & 0.0320 & 0.0002 & 0.7551 \\
\hline
\end{tabular}




\section{Results}

\subsection{Wind speed profile, radiometer and MODIS estimates of wind friction velocity}

We found large temporal variability in $u^{*}$ profile $/ U_{h}$ for the JER playa and Harrisburg open shrubland sites. Normalizing $u^{*}$ profile by $U_{h}$ removed the influence of wind speed variation and revealed the variability in surface aerodynamic roughness. As expected, $u^{*}$ profile $/ U_{h}$ at the bare JER playa site was smaller than $u^{*}$ profile/ $U_{h}$ at the Harrisburg open shrubland site (Table 1). The temporal variability of $u^{*}$ profile/ $U_{h}$ at both sites did not concide with the timing of seasonal vegetation changes. The large variability in $z o$ was due to wind direction, as shown by standardized $z o$ anomalies (Figure 3), indicating that a different areal extent of heterogeneous roughness was influencing $u^{*}$ profile/ $U_{h}$ to a greater degree than seasonal changes in roughness (Table 2).

In contrast, variability in albedo-derived estimates of $u^{*} / U_{h}$ were much smaller than those derived from wind speed profiles (Table 1). Radiometer-derived estimates of $u_{s}{ }^{*} \mathrm{rad} / U_{h}$ were similar to $u^{*} \mathrm{rad} / U_{h}$ at both the JER playa and Harrisburg open shrubland sites. The small variability in $u$ $s^{*} \mathrm{rad} / U_{h}$ and $u^{*} \mathrm{rad} / U_{h}$ represents the defined and fixed area $\left(314.16 \mathrm{~m}^{2}\right.$ fields-of-view) of the radiometer estimates, that encompassed bare soil surfaces at both sites. Large roughness (e.g., vegetation) outside the fieldsof-view had no effect on the estimates of $u_{s^{*} \mathrm{rad}} / U_{h}$ or $u^{*} \mathrm{rad} / U_{h}$, and so produced no drag partition. The estimates integrated only the effects of spatial variability in surface roughness within the fields-of-view of the radiometers.

Importantly, we found that estimates of $u^{*} / U_{h}$ and $u_{s *} / U_{h}$ obtained from the albedo approach were consistent with those obtained from wind speed profiles (Figure 4), indicating that the albedo approach, established at the scale of the wind tunnel, can be applied at the field scale. At the JER playa site, $u_{s^{*} \mathrm{rad}} / U_{h}$ and $u^{*} \mathrm{rad} / U_{h}$ estimates were in the middle of the range of $u^{*}$ profile $/ U_{h}$ (Figure 4 , top panel). The $u_{s^{*} \text { modis }} / U_{h}$ values were closer to $u^{*}$ profile/Uh while $u^{*}$ modis/Uh were larger than the $u^{*}$ profile/Uh estimates at the JER playa site (Table 1). At the JER Harrisburg open shrubland site, $u_{s^{*} \mathrm{rad}} / U_{h}$ and $u^{*} \mathrm{rad} / U_{h}$ were smaller than $u^{*}$ profile/Uh, while MODIS estimates of $u^{*}$ modis/Uh were in the middle of the range of $u^{*}$ profile/Uh (Table 1 ). The $u^{*}$ modis/Uh were of similar magnitude at both sites. The results demonstrate 
that, at the JER playa site, the influence of vegetation on the wind speed profile measurements was small and $u^{*}$ profile/ $U_{h}$ was approximated by $u_{s^{*}} / U_{h}$. This is because vegetation was very sparse or absent within approximately $100 \mathrm{~m}$ of the tower and so the $u^{*}$ profile/Uh described the bare playa surface. At the JER Harrisburg open shrubland site, both $u^{*}$ modis $/ U_{h}$ and $u^{*}$ profile/ $U h$ were influenced by surrounding vegetation and produced similar values on average while $u_{s}^{*}$ modis $/ U_{h}$ was much smaller due to momentum partitioning. The $u^{*}$ modis/ $U h$ at the JER playa site described the broader $500 \mathrm{~m}$ MODIS pixel, including the surrounding vegetation and dune ridges. However, these features appear to have had minimal effect on the $u^{*}$ profile/Uh measurements as evidenced by the small values and small variability in $z o$ at that site (Table 2).

Figure 3. Standardized $z_{0}$ anomalies plotted against wind direction for the JER and National Wind Erosion Network (NWERN) sites from April to September 2018. Data were filtered to remove obstruction from the meteorological tower $\left(350^{\circ}\right.$ to $10^{\circ}$ from north for the NWERN sites and $340^{\circ}$ to $20^{\circ}$ from north for the JER sites and the CPER site).

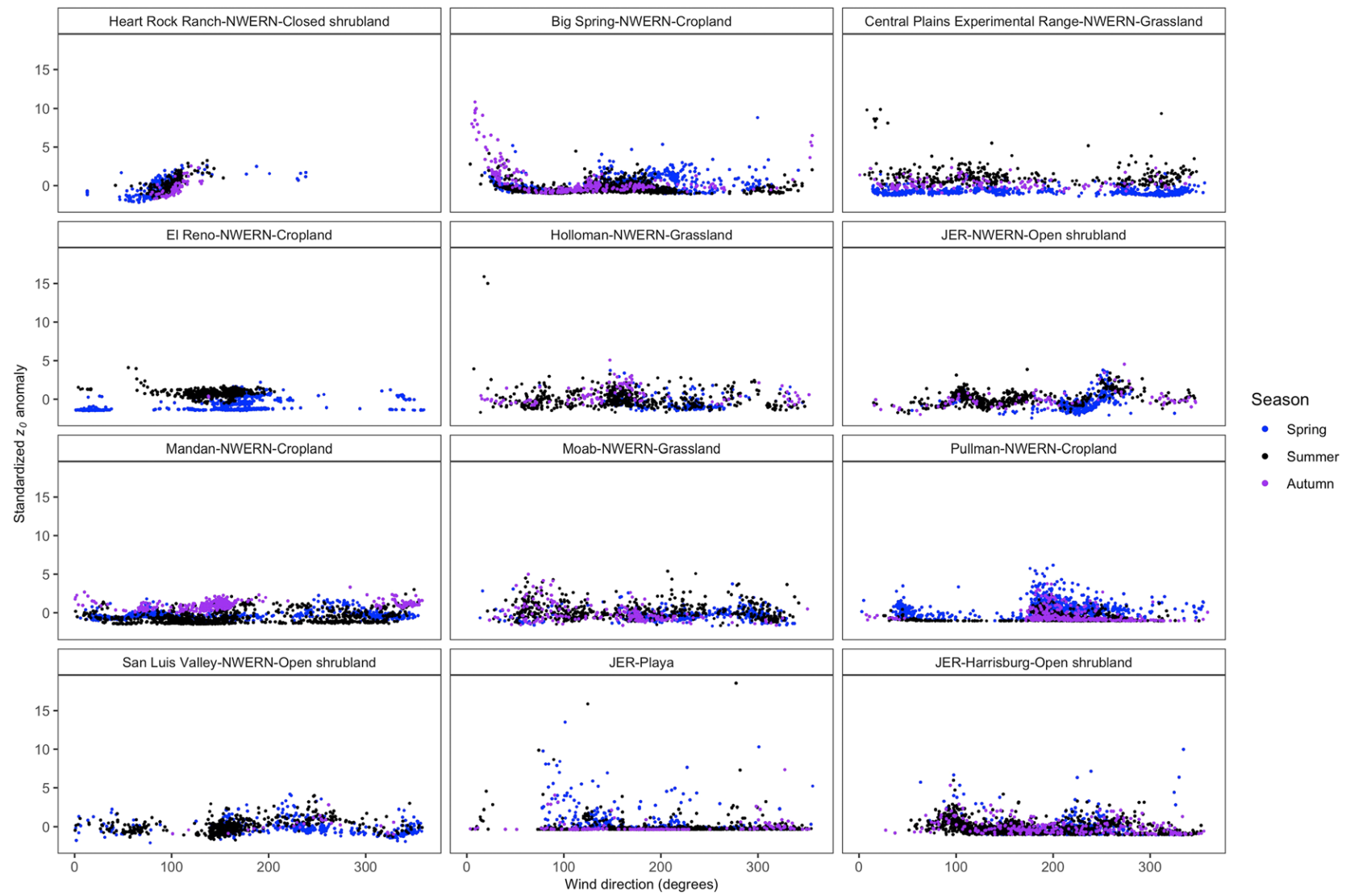




\subsection{Friction velocities across land cover types}

Albedo-derived estimates of $u^{*}$ modis $/ U h$ were consistent with $u^{*}$ profile $/ U_{h}$ ( \pm $0.003-0.023$ ) across diverse land cover types sampled by NWERN sites, plotting close to the 1:1 line (Figure 5). However, $u^{*}$ profile $/ U_{h}$ values were considerably larger than $u_{s}{ }^{*}$ modis $/ U_{h}$ values (ranging from +0.009 to +0.083 ). Consistent with understanding of momentum partitioning over vegetated surfaces, these results show that estimates of $z o$ and $u^{*} / U_{h} \mathrm{ob}-$ tained from wind speed profiles described the total site roughness and $u^{*}$ but poorly described $u_{s^{*}}$ that drives aeolian sediment transport. Estimates of $u_{s^{*}}$ at the sites would require a drag partition correction to the estimate of $u^{*}$. Across the broad range of land cover types sampled at the NWERN sites, zo showed large variability within and among sites (Table 2).

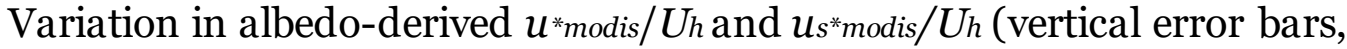
Figure 5) was smaller than for $u^{*}$ profile $/ U_{h}$ (horizontal error bars, Figure 5) across the sites. Variability in the albedo-derived estimates was due mainly to temporal variations in aerodynamic roughness in response to seasonal vegetation growth, senescence, and planting and harvesting at the grassland and cropland sites (Table 2, Figure 3). At the cropland sites, there is a general increase in the mean and median zo from spring to autumn. The \% CV was generally large for all sites, indicating large changes in roughness. For example, at the Pullman NWERN site, the large \% CV in summer indicates harvest, as the mean zo decreases from 0.022 to 0.006 . The grassland sites maintained fairly consistent mean zo values throughout the year, with the exception of the Central Plains Experimental Station (shortgrass steppe), which showed an increase in zoin the summer months. The trend was similar for the median zovalues for the grassland sites. The seasonal change in mean and median zo was smallest at the shrubland sites, with some sites showing a slight increase from spring to autumn, consistent with herbaceous vegetation growth. While we identified patterns in wind speed profile-derived zo within land cover types, we found no similarly consistent pattern among land cover types, suggesting that different combinations of vegetation cover and structure (height, spacing) may produce overlapping, or different, distributions of $u^{*} / U h$. As the variability in

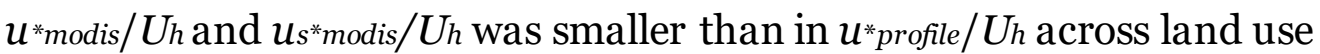
and land cover types, differences in areal $u^{*} / U_{h}$ and $u_{s^{*}} / U_{h}$ among sites are potentially more detectable when derived from surface albedo than wind speed profiles at a single location. 
Table 2. Summary of aerodynamic roughness lengths $\left(z_{0}\right)$ estimated from wind speed p rofiles at the Jornada Experiment Range (JER) and National Wind Erosion Research Network (NWERN) sites (CV = coefficient of variance).

\begin{tabular}{|c|c|c|c|c|c|c|c|c|}
\hline \multirow[b]{2}{*}{ Site name } & & \multirow{2}{*}{$\begin{array}{l}\text { IGBP land } \\
\text { cover class }\end{array}$} & \multirow[b]{2}{*}{ Latitude } & \multirow[b]{2}{*}{ Longitude } & \multicolumn{4}{|c|}{$z_{0}(\mathrm{~m})$} \\
\hline & & & & & Mean & Median & Variance & $\mathrm{CV} \%$ \\
\hline \multirow[t]{4}{*}{ JER NWERN site, NM } & Annual & \multirow{4}{*}{$\begin{array}{l}\text { Open } \\
\text { shrubland }\end{array}$} & \multirow[t]{4}{*}{32.63} & \multirow[t]{4}{*}{-106.74} & 0.0660 & 0.0622 & 0.0007 & 39 \\
\hline & Spring & & & & 0.0599 & 0.0555 & 0.0006 & 41 \\
\hline & Summer & & & & 0.0701 & 0.0663 & 0.0006 & 35 \\
\hline & Autumn & & & & 0.0688 & 0.0622 & 0.0015 & 57 \\
\hline \multirow[t]{4}{*}{ San Luis Valley, CO } & Annual & \multirow{4}{*}{$\begin{array}{l}\text { Open } \\
\text { shrubland }\end{array}$} & \multirow[t]{4}{*}{37.59} & \multirow[t]{4}{*}{-105.69} & 0.0392 & 0.0358 & 0.0002 & 40 \\
\hline & Spring & & & & 0.0374 & 0.0329 & 0.0003 & 48 \\
\hline & Summer & & & & 0.0403 & 0.0375 & 0.0002 & 34 \\
\hline & Autumn & & & & 0.0449 & 0.0431 & 0.0002 & 33 \\
\hline \multirow[t]{4}{*}{ JER Harrisburg site, NM } & Annual & \multirow{4}{*}{$\begin{array}{l}\text { Open } \\
\text { shrubland }\end{array}$} & \multirow[t]{4}{*}{32.61} & \multirow[t]{4}{*}{106.73} & 0.0085 & 0.0066 & $6.48 \times 10^{-5}$ & 95 \\
\hline & Spring & & & & 0.0083 & 0.0061 & $8.18 \times 10^{-5}$ & 109 \\
\hline & Summer & & & & 0.0084 & 0.0069 & $5.70 \times 10^{-5}$ & 90 \\
\hline & Autumn & & & & 0.0095 & 0.0072 & $6.68 \times 10^{-5}$ & 86 \\
\hline \multirow[t]{4}{*}{ Heart Rock Ranch, ID } & Annual & \multirow{4}{*}{$\begin{array}{l}\text { Closed } \\
\text { shrubland }\end{array}$} & \multirow[t]{4}{*}{43.42} & -114.35 & 0.2137 & 0.2085 & 0.0014 & 17 \\
\hline & Spring & & & & 0.2140 & 0.2072 & 0.0018 & 20 \\
\hline & Summer & & & & 0.2171 & 0.2120 & 0.0011 & 15 \\
\hline & Autumn & & & & 0.2001 & 0.1968 & 0.0010 & 16 \\
\hline Holloman, NM & Annual & Grassland & 32.94 & -106.11 & 0.0519 & 0.0479 & 0.0004 & 37 \\
\hline & Spring & & & & 0.0454 & 0.0405 & 0.0003 & 36 \\
\hline & Summer & & & & 0.0524 & 0.0484 & 0.0004 & 37 \\
\hline & Autumn & & & & 0.0626 & 0.0579 & 0.0003 & 30 \\
\hline Moab, UT & Annual & Grassland & 38.65 & -109.87 & 0.0208 & 0.0183 & 0.0001 & 55 \\
\hline & Spring & & & & 0.0160 & 0.0149 & $6.88 \times 10^{-5}$ & 52 \\
\hline & Summer & & & & 0.0242 & 0.0213 & 0.0001 & 50 \\
\hline & Autumn & & & & 0.0197 & 0.0162 & 0.0001 & 55 \\
\hline Central Plains & Annual & Grassland & 40.83 & -104.69 & 0.0566 & 0.0501 & 0.0010 & 57 \\
\hline Experimental Range, $\mathrm{CO}$ & Spring & & & & 0.0361 & 0.0315 & 0.0003 & 48 \\
\hline & Summer & & & & 0.0856 & 0.0798 & 0.0010 & 37 \\
\hline & Autumn & & & & 0.0523 & 0.0499 & 0.0003 & 30 \\
\hline El Reno, OK & Annual & Cropland & 35.56 & -98.04 & 0.1010 & 0.1256 & 0.0041 & 63 \\
\hline & Spring & & & & 0.0701 & 0.0379 & 0.0035 & 85 \\
\hline & Summer & & & & 0.1537 & 0.1518 & 0.0007 & 17 \\
\hline & Autumn & & & & 0.0687 & 0.0536 & 0.0030 & 80 \\
\hline Mandan, ND & Annual & Cropland & 46.78 & -100.95 & 0.0516 & 0.0454 & 0.0011 & 65 \\
\hline & Spring & & & & 0.0429 & 0.0385 & 0.0006 & 58 \\
\hline & Summer & & & & 0.0407 & 0.0335 & 0.0009 & 74 \\
\hline & Autumn & & & & 0.0852 & 0.0807 & 0.0008 & 33 \\
\hline Pullman, WA & Annual & Cropland & 46.89 & -118.29 & 0.0154 & 0.0111 & 0.0002 & 95 \\
\hline & Spring & & & & 0.0217 & 0.0193 & 0.0002 & 73 \\
\hline & Summer & & & & 0.0063 & 0.0039 & $4.57 \times 10^{-5}$ & 108 \\
\hline & Autumn & & & & 0.0116 & 0.0079 & 0.0001 & 94 \\
\hline Big Spring, TX & Annual & Cropland & 32.27 & -101.49 & 0.0087 & 0.0065 & $6.31 \times 10^{-5}$ & 91 \\
\hline & Spring & & & & 0.0082 & 0.0068 & $3.84 \times 10^{-5}$ & 76 \\
\hline & Summer & & & & 0.0066 & 0.0057 & $2.39 \times 10^{-5}$ & 74 \\
\hline & Autumn & & & & 0.0188 & 0.0159 & 0.0002 & 71 \\
\hline JER Playa site, NM & Annual & Playa & 32.58 & -106.68 & 0.0011 & 0.0002 & $9.89 \times 10^{-6}$ & 283 \\
\hline & Spring & & & & 0.0016 & 0.0003 & $1.54 \times 10^{-5}$ & 246 \\
\hline & Summer & & & & 0.0008 & $9.67 \times 10^{-5}$ & $6.01 \times 10^{-6}$ & 322 \\
\hline & Autumn & & & & 0.0009 & $6.32 \times 10^{-5}$ & $5.28 \times 10^{-6}$ & 256 \\
\hline
\end{tabular}




\subsection{Comparison of friction velocities measured in the field and wind tunnel}

To provide a second, independent, test of the albedo model, we compared MODIS albedo for the NWERN sites and coincident measurements of wind speed profile-derived friction velocities with Marshall's (1971) wind tunnel measurements underpinning the albedo model. Using MODIS albedo we retrieved the daily $\omega n s$ at each of the NWERN sites that characterized the roughness elements across scales from the bed roughness, soil aggregates and clods, rock fragments, and vegetation (grasses, forbs, shrubs and crop varieties). The $\omega n s$ was then plotted against the independently measured wind speed profile-derived $u^{*}$ profile $/ U_{h}$ (Figure 6). We plotted Marshall's (1971) estimates of $u^{*} / U_{h}$ in a laboratory wind tunnel against MODIS $\omega_{n s}$ and then plotted the models fitted to Marshall's (1971) $u^{*} / U_{h}$ and $u_{s^{*}} / U_{h}$ data. Consistency in the distribution of Marshall's (1971) measurements, and the distribution of independently measured $u^{*}$ profile $/ U_{h}$ and $\omega n$ s from the field sites, provides confirmation that surface shadowing obtained from albedo can predict $u^{*}$ and $u_{s^{*}}$ across scales of roughness (i.e., from the wind tunnel with small scales of roughness to different land cover types in the field with a range of roughness scales). The measured $u^{*}$ profile $/ U_{h}$ data all plot close to $u^{*} / U_{h}$ indicating that the wind speed profile is strongly influenced by surface roughness and that, consistent with theory, a drag partition correction is necessary to estimate $u s^{*} / U_{h}$ for calculating sediment transport. The remaining discrepancy between the NWERN $u^{*}$ profile/ $U h$ and Marshall's data was expected given the difference in estimation methods (i.e., single location estimates from the wind speed profiles and areal estimates from the model). These results suggest that by normalizing the $u^{*}$ and $u_{s^{*}}$ at a site by $U h$, this metric of the surface aerodynamic roughness, and the momentum partition, can be expressed as a function of surface shadowing irrespective of the size of roughness elements populating the surface.

The distribution of the $u^{*}$ profile / $U h$ data between the NWERN sites and their error bars is instructive. This variability is inherent in profile-based measurements, consistent with Figure 4, and can be interpreted as changing roughness at a given site, e.g., following crop planting and harvesting, in addition to its spatial heterogeneity. Sites with more roughness, and thus more surface shadowing, fall toward the right of the plot where $u^{*}$ profile $/ U_{h}$ is closer to the total shear stress, $u^{*}$, and momentum partitioning is large (Figure 6). Open shrubland and conventional tillage cropland sites with large spaces between roughness elements and/or fallow soils, produced 
less shadow (aerodynamic sheltering) consistent with measured $u^{*}$ profile $/ U h$ having large variability between $u^{*}$ and $u_{s^{*}}$. In these situations, $u^{*}$ profile $/ U_{h}$ represented $u^{*} / U_{h}$ or $u_{s^{*}} / U_{h}$ over bare soil patches depending on wind direction and time of year, so its variability was large and spanned the albedo model response following Marshall's (1971) measurements.

Figure 4. At the Jornada Experimental Range playa site (top panel) and Harrisbur open shrubland site (bottom panel), $\mathrm{u} * / \mathrm{Uh}$ estimated using the traditional approach of the wind speed profile (blue line), $u_{*} /$ Uh estimated using the new albedo-based ap proach from radiometer data (black line), $u_{s \star} /$ Uh estimated using the albedobased approach from radiometer data (purple line), $u * /$ Uh estimated using the alb edo-based approach from MODIS data (orange line), and $\mathrm{u}_{\mathrm{s}} /$ Uh estimated using the albedo-based approach from MODIS data (gray line). Not that $u *$ rad/Uh and us * rad/Uh are consistent (overlap) for both the playa and open shrubland sites.
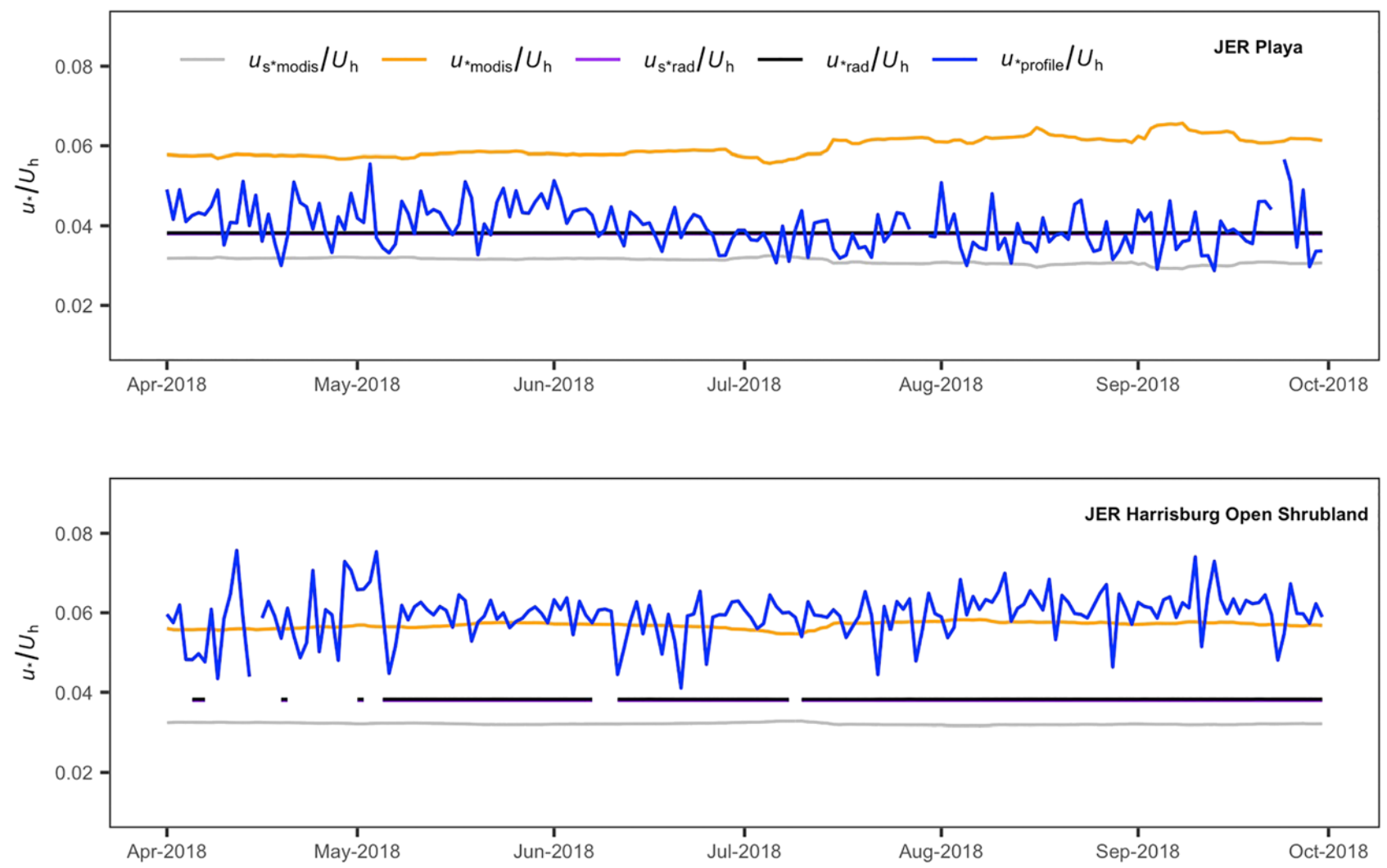
Figure 5. MODIS albedo-based $u_{*} / U h$ and $u_{s^{*}} / U h$ plotted against wind speed profilebased $u_{*} / U h$ for the JER sites and the National Wind Erosion Network sites April th rough September 2018. Uncertainty (standard deviation) in MODIS estimates is sh own in the vertical error bars. Uncertainty (standard deviation) in wind speed profile-based estimates is shown in the horizontal error bars. The 1:1 line shows the relation between MODIS albedo-based and wind speed profile-based estimates, revealing that the latter most closely estimates the $u * / U h$ at the sites.

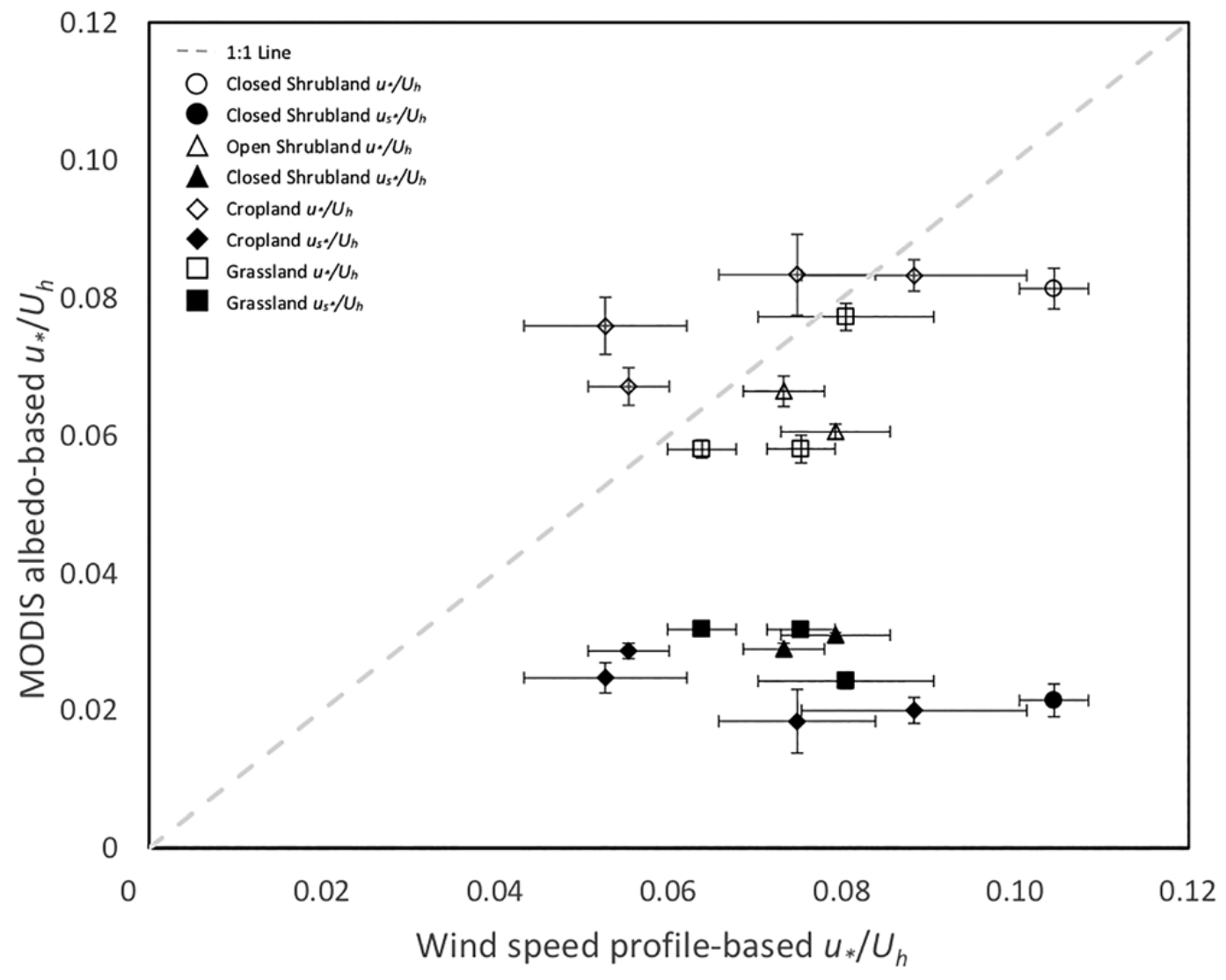


Figure 6. Profile-based $u * / U h$ plotted against normalized shadow, wns for the National Wind Erosion Network sites April through September 2018. Uncertainty (standard deviation) in profile estimates of $u_{*} / U h$ is shown in the vertical error bars. Uncertainty (standard deviation) in whs is shown in the horizontal error bars. The

$u * / U h$ (solid line) and $u_{s *} / U h$ (dashed line) represent an idealized curve of the equations from the albedo model. The data Chappell and Webb (2016) used to calibrate the albedo model, from Marshall (1971) is also plotted. With a drag partition applied, Marshall's shear stress data shows a strong relationship between measured shear stresses (scaled by $U h$ ) and $\omega_{\text {ns }}$ and trends with the albedo model.

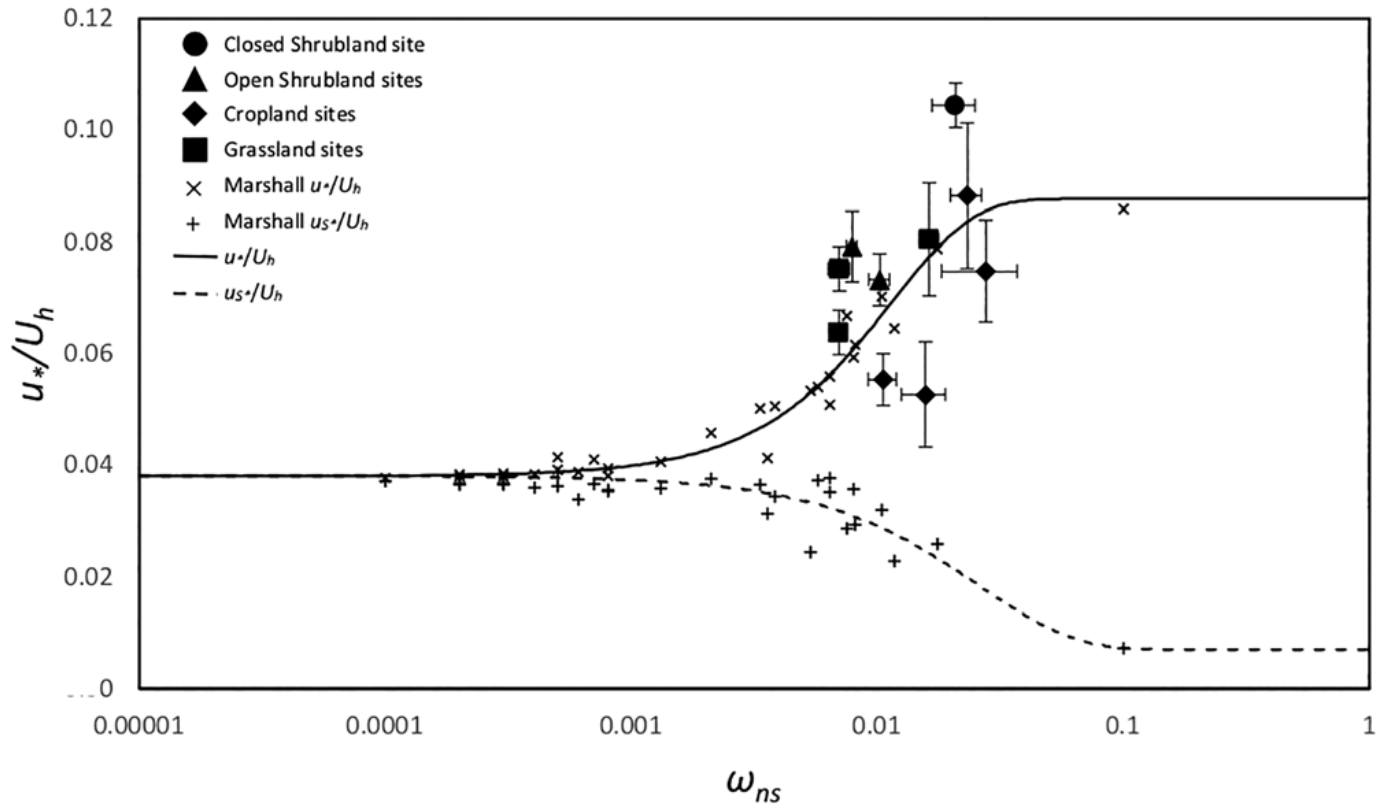




\section{Discussion}

Using measurements of wind speed and land surface albedo, we performed the first field test of an albedo approach to estimating areal $u^{*} / U_{h}$ and $u_{s^{*}} / U_{h}$ using two independent datasets: 1 ) estimates of wind friction velocity from field sites at the Jornada Experimental Range and across diverse land cover types sampled by the National Wind Erosion Research Network (Figures 4 and 5); and 2) MODIS land surface albedo and wind speed profile-derived $u^{*} / U_{h}$ at NWERN sites compared with Marshall's (1971) wind tunnel measurements underpinning the albedo model (Figure 6). We showed that field and satellite measurements of surface albedo can be used to obtain values of $u^{*} / U_{h}$ and $u_{s^{*}} / U_{h}$ across roughness scales that are consistent with those produced in the wind tunnel.

We quantified the variability in surface aerodynamic roughness (zo) across land cover types and evaluated how surface albedo can be used to estimate the areal partition of wind momentum and surface wind friction velocities. Our results showed large variability in estimates of surface $z o$ and $u^{*}$ profile within and among different land cover types. This variability was due to heterogeneity in the distribution of roughness elements relative to wind direction (Figure 3). Additional sources of $z o$, and $u^{*}$ variability may be introduced during data analysis because the law-of-the-wall is only valid under certain conditions: 1) winds are unidirectional within a stable boundary layer, 2) wind speed is averaged over a sufficiently long time period to capture variability in turbulence, and 3) roughness height, zo, is calculated during non-saltation periods so that saltation does not influence roughness height (Martin and Kok, 2018). Bauer et al. (1992) identified measurement errors due to inaccuracy and imprecision of equipment and post-processing statistical errors during regression to contribute further to variability. Together, these sources of variability produce uncertainty in $z_{0}$ estimates for land cover types that may be propagated through models. The albedo approach enables direct areal estimates that reduce the uncertainty in $u^{*} / U_{h}$ and $u_{s^{*}} / U_{h}$ in support of spatial wind erosion and dust emission modeling. A recognized caveat of the albedo approach is that it does not represent effects of roughness on $u^{*}$ and $u s^{*}$ in particular wind directions. Resolving directional roughness effects over land surface areas remains a long-standing challenge for the wind erosion and dust modeling community. 
We found that, consistent with theory (e.g., Raupach, 1992), $u^{*}$ profile $/ U_{h}$ over aerodynamically rough land surfaces describes the total wind friction velocity $\left(u^{*}\right)$ and requires correcting using a drag partition to estimate $u s^{*}$ that drives aeolian sediment transport. The large spatial and temporal variability in $z o$ and $u^{*}$ profile $/ U h$, and need to apply a drag partition, limit the utility of the variables for understanding and modeling areal aeolian transport over aerodynamically rough surfaces. While $u^{*}$ profile $/ U_{h}$ describes the wind response to roughness from different directions, the model of Chappell and Webb (2016) enables areal estimates of $u_{s^{*}} / U h$ directly using land surface albedo, without the need for a separate drag partition because it is inherent in the original calibration (Figure 5). These estimates integrate roughness heterogeneity across sensor fields-of-view and viewing angles, thereby enabling areal estimates that can be used to improve model parameterization. We found the albedo model estimates of $u^{*} / U_{h}$ and $u_{s} * / U_{h}$ were consistent with field measurements across land cover types (Figure 4) and that independently measured albedo and $u^{*} / U_{h}$ were consistent with wind tunnel measurements of the drag partition.

The spatial distribution of wind shear stress over the land surface, and its partitioning between roughness elements and the bed, is typically highly variable (King et al., 2006; Gillies et al., 2007; Brown et al., 2008; Webb et al., 2014a). Heterogeneity in surface roughness and changing wind direction mean that, for aerodynamically smooth sites (e.g., the JER playa site), $u^{*}$ profile/Uh represents $u_{s} * / U_{h}$. However, for aerodynamically rough locations, $u^{*}$ profile $/ U_{h}$ predominantly represents $u^{*} / U_{h}$. Our results show that estimating area-integrated $u^{*} / U_{h}$ and $u_{s^{*}} / U_{h}$ directly from surface shadowing obtained from albedo (i.e., Eqs. 3 and 4) provides an alternative approach to obtaining the aerodynamic properties for a land surface area. Because albedo is measured over an area, derived estimates of surface shadowing (Chappell \& Webb, 2016) inherently integrate the effects of roughness heterogeneity within sensor fields-of-view, e.g., field radiometer to satellite sensor. When measured over relatively smooth bare soil surfaces using a net radiometer, we found that albedo-derived $u^{*} / U_{h}$ and $u_{s^{*}} / U_{h}$ were approximately the same, consistent with the absence of momentum partitioning. This is also because the anisotropic influence of aerodynamic roughness is removed in the albedo-based estimates. When measured over aerodynamically rough land surfaces by MODIS, we found that albedo-derived $u^{*} / U_{h}$ and $u_{s^{*}} / U_{h}$ were different due to momentum partitioning and $u^{*}$ modis $/ U_{h}$ was consistent with the mean values of $u^{*}$ pro- 
file/Uh that were more variable due to the influence of roughness heterogeneity and wind direction. These results demonstrate the need for and benefit of using albedo to estimate total and soil surface wind friction velocities. In contrast, $u^{*}$ profile/ $U_{h}$ measured at single tower locations require drag partitioning corrections but those available are inherently unreliable particularly over large areas and across scales or invoke crude approximations which make aeolian sediment transport models highly uncertain.

Importantly, we found single-point estimates of $u^{*}$ profile/ $U_{h}$ across diverse land cover types were consistent with the magnitude of $u^{*}$ measured by Marshall (1971) for their respective surface shadowing obtained independently from albedo (Figure 6). This consistency demonstrates that the albedo model is partitioning momentum correctly across different scales of roughness (e.g., from vertical scales of $\mathrm{mm}$ in the wind tunnel to 10's of $\mathrm{m}$ within landscapes). We found proportional surface shadowing (sheltering) produced by open shrubland sites could be similar to some grassland and cropland sites depending on their roughness structures. The implication of this finding is that surface albedo may be used to directly estimate $u^{*} / U_{h}$ and $u_{s^{*}} / U_{h}$ over the entire range of surface roughness occurring in natural environments or from laboratory to field.

Finally, comparing $u^{*}$ profile $/ U_{h}$ with Marshall's (1971) $u^{*} / U_{h}$ wind tunnel data revealed that there are unexplained second-order differences between the wind tunnel data and the field data. Some of the field estimates of $u^{*} / U_{h}$ fall in line with the model, while others do not (e.g., two of the cropland sites and the closed shrubland site). The differences between $u^{*}$ profile $/ U_{h}$ and Marshall's data could be explained by a) the wind speed profile measurements from a single location at each site did not provide a robust sample of $u^{*}$ profile $/ U_{h}$ over an area and were influenced by wind direction, b) the field sites had multiple scales of roughness (vegetation, rocks, and soil) that were not included in Marshall's wind tunnel measurements, and/or c) Marshall's data and therefore the albedo model do not capture the full range of drag partition responses produced in the field. The first is probable, since estimation of $u^{*}$ profile $/ U_{h}$ from a single sample location is unlikely to represent variability across an entire site due to changes in wind direction over heterogeneous roughness. This would imply that there is even larger variability in $u^{*}$ profile/ $U_{h}$ than we have measured and that a larger sample size would be required to adequately characterize $z o$ and $u^{*}$ for a given area of each respective land cover type. It 
is also possible that different roughness conditions in the field can produce different drag partition responses that were not described by Marshall's data and therefore in the albedo model. This raises the hypothesis that observed differences between wind speed profile-derived $u^{*} / U_{h}$ from a single point in a landscape to areal estimates of $u^{*} / U_{h}$ produced by the albedo model would be expected given that the area described by each approach is different. These results suggest the importance of further validating the Chappell and Webb (2016) model against areal measurements of shear stress in the field, including environments with different roughness element sizes, configurations and densities. Such measurements could follow approaches established by Gillies et al. (2006), King et al. (2006) and Gillies et al. (2007) to sample the spatial distribution of surface shear stress for comparison with in situ (e.g., tower-mounted net radiometer) and satellite (e.g., MODIS) retrievals of surface albedo and shadowing. Relating the spatial distribution of surface shear stress and albedo to aeolian sediment transport rates could test the predictive capability of the Chappell and Webb (2016) model to include effects on sediment transport and dust emission and address existing large uncertainties arising from model assumptions of spatially and temporally constant aerodynamic roughness across land cover types.

The results of this study provide evidence that the albedo approach can be used to obtain areal estimates of $u^{*}$ and $u_{s^{*}}$ that are consistent with field and wind tunnel measurements. This study confirms that single-point estimates of $u^{*} / U_{h}$ from wind speed profiles provide information on the sensitivity of $u *$ to roughness heterogeneity from an undefined area in a given wind direction and provide information needed to understand the processes governing sediment transport at a single point in a landscape. This approach cannot, however, directly estimate wind friction velocity at the soil surface, $u_{s^{*}}$, which is critical for understanding and predicting aeolian sediment transport over an area. Additionally, the traditional approach is limited for understanding large areas (e.g., > 1 ha) because the estimates of $u^{*}$ represent a changing and unknown upwind fetch. In contrast, the albedo approach produces estimates of $u^{*} / U_{h}$ and $u_{s^{*}} / U_{h}$ over an area that is flexible depending on sensor field-of-view (e.g., field radiometer to satellite). The approach enables integration of heterogeneous roughness effects over space, reducing the variability inherent in profile-derived estimates of $u^{*}$. Further quantitative evidence is required to assess the sensitivity of the albedo model to different configurations and heterogeneous scales of roughness across land cover types. 


\section{Conclusions}

Existing dust emission and wind erosion models use estimates of zo either from field measurements which are not representative of an area, or select values from look-up tables that are generalized and often static across land cover types. This approach is flawed by the inherent feedback of $z o$ : as wind speed increases the influence of (vertical) roughness decreases. Field measurements of $z o$ and $u^{*}$ at single locations are highly variable, influenced by an unspecified roughness area and wind direction, and require a drag partition correction to obtain $u_{s^{*}}$. Consequently, crude estimates of $u s^{*}$ produce large uncertainty and inaccurate estimates of aeolian sediment transport over land surface areas. In this study, we examined measurements of wind speed and land surface albedo from a wide range of land cover types. Applying the Prandtl-von Kármán logarithmic velocity profile law (Eq. 1) to wind speed profiles produced large variability in estimates of $z o$ and $u^{*}$ in response to anisotropic heterogeneity in roughness due to changing wind direction and fetch. Using shadow (the complement of albedo), we derived areal estimates of $u^{*} / U_{h}$ and $u_{s^{*}} / U_{h}$ which integrated the effects of roughness over an area and were therefore less variable than the wind speed profiles. Consistent with theory, we found that wind speed profiles provide accurate but imprecise estimates of $u_{s^{*}}$ over smooth surfaces (e.g. the JER playa site) but provide inaccurate and imprecise estimates of $u^{*}$ over aerodynamically rough surfaces. We tested the ability of the albedo model to cut across scales by comparing independent measurements of surface albedo obtained in the field and $u^{*} / U_{h}$ with the wind tunnel measurements of Marshall (1971). Our results reveal the applicability of the albedo model at the field scale and suggest that it can be applied across scales of roughness. Further field experiments will evaluate the albedo model against spatial measurements of surface shear stress across different scales of heterogeneous roughness. 


\section{References}

André, J-C., \& Blondin, C. (1986). On the effective roughness length for use in numerical three-dimensional models. Boundary-Layer Meteorology 35(3), 231-245.

Bauer, B.O., Sherman, D.J., \& Wolcott, J.F. (1992). Sources of uncertainty in shear stress and roughness length estimates derived from velocity profiles. Professional Geographer 44(4), 453-464.

Bergametti, G., \& Gillette, D.A. (2010). Aeolian sediment fluxes measured over various plant/soil complexes in the Chihuahuan desert. JournalofGeophysical Research 115, F03044. https://doi.org/10.1029/2009JF001543

Brown, S., Nickling, W.G., \& Gillies, J.A. (2008). A wind tunnel examination of shear stress partitioning for an assortment of surface roughness distributions. Journal of Geophysical Research 113, Fo2So6. https://doi.org/10.1029/2007JFo00790

Bulloch, Jr., H.E., \& Neher, R.E. (1980). Soil Survey of Dona Ana County Area New Mexico. United States Department of Agriculture, Soil Conservation Service.

Chappell, A., McTainish, G., Leys, J., \& Strong, C. (2003). Simulations to optimize sampling of aeolian sediment transport in space and time for mapping. Earth Surface Processes and Landforms: the Journal of the British Geomorphological Research Group 28(11), 1223-1241.

Chappell, A., \& Heritage, G.L. (2007). Using illumination and shadow to model aerodynamic resistance and flow separation: An isotropic study. Atmospheric Environment 41, 5817-5830.

Chappell, A., Van Pelt, S.,Zobeck, T., \& Dong, T. (2010). Estimating aerodynamic resistance of rough surfaces using angular reflectance. Remote Sensing of Environment 114, 1462-1470.

Chappell, A., \&Webb, N.P.(2016). Using albedo to reform wind erosion modelling, mapping, and monitoring. Aeolian Research 23, 63-78.

Chappell, A., Webb, N.P., Guerschman, J.P., Thomas, D.T., Mata, G., Handcock, R.N., Leys, J.F., \& Butler, H.J. (2018). Improving ground cover monitoring for wind erosion assessment using MODIS BRDF parameters. Remote Sensing of Environment 204, 756-768.

Cho, J., Miyazaki, S., Yeh, P.J.F., Kim, W., Kanae, S., \& Oki, T. (2012). Testing the hypothesis on the relationship between aerodynamicroughness length and albedo using vegetation structure parameters. InternationalJournal of Biometeorology 56, 411-418.

Dupont, S., Rajot, J-L., Labiadh, M., Bergametti, G., Alfaro, S.C., Bouet, C., etal. (2018). Aerodynamic parameters over an eroding bare surface: reconciliation of the law of the wall and eddy covariance determinations. Journal of Geophysical Research Atmospheres 123(9), 4490-4508. 
Gillette, D.A., Herrick, J.E., \& Herbert, G.A. (2006). Wind characteristics of mequite streets in the northern Chihuahuan Desert, New Mexico, USA. Environmental Fluid Mechanics 6, 241-275. https://doi.org/10.1007/s10652-005-6022-7

Gillies, J.A., Nickling, W.G., \& King, J. (2006). Aeolian sediment transport through large patches of roughness in the atmosphericinertial sublayer. Journal of Geophysical Research: Earth Surface 111, Fo2006. https://doi.org/10.1029/2005JFoo0434

Gillies, J.A., Nickling, W.G., \& King, J. (2007). Shear stress partitioning in large patches of roughness in the atmospheric inertial sublayer. Boundary-Layer Meteorology 122, 367-396.

Greeley, R., Gaddis, L., Lancaster, N., Dobrovolskis, A., Iversen, J., Rasmussen, K., et al. (1991). Assessment of aerodynamic roughness via airborne radar observations. Aeolian Grain Transport, 77-88.

Greeley, R., Blumberg, D.G., McHone, J.F., Dobrovolskis, A., Iversen, J.D., Lancaster, N., et al. (1997). Applications of spaceborne radar laboratory data to the study of Aeolian processes. Journal of Geophysical Research 102(E5), 10971-10983.

King, J., Nickling, W.G., \& Gillies, J.A. (2006). Aeolian shear stress ratio measurements within mesquite-dominated landscapes of the Chihuahuan Desert, New Mexico, USA. Geomorphology 82, 229-244.

Kipp \& Zonen B.V. (2002). CNR1 Net radiometer: Instruction Manual. Delft, Holland.

LeGrand, S.L., Polashenski, C., Letcher, T.W., Creighton, G.A., Peckham, S.E., \& Cetola, J.D. (2019). The AFWAdust emission scheme for the GOCART aerosol model in WRF-Chem v3.8.1. Geoscientific Model Development 12.1,131-166.

Li, J., Okin, G.S., Herrick, J.E., Belnap, J., Miller, M.E., Vest, K., etal. (2013). Evaluation of a new model of aeolian transport in the presence of vegetation. Journal of Geophysical Research: Earth Surface 118(1), 288-306.

Marshall, J.K.(1971). Drag measurements in roughness arrays of varying density and distribution. Agricultural Meteorology 8, 269-292.

Marticorena, B., \& Bergametti, G. (1995). Modeling the atmospheric dust cycle: 1. Design of a soil-derived dust emission scheme. Journal of GeophysicalResearch $100(D 8), 16415^{-16430 .}$

Marticorena, B., Chazette, P., Bergametti, G., Dulac, F., \& Legrand, M. (2004). Mapping the aerodynamic roughness length of desert surfaces from the POLDER/ADEOS bi-directional reflectance product. International Journal of Remote Sensing 25(3), 603-626.

Marticorena, B., Kardous, M., Bergametti, G., Callot, Y., Chazette, P., Khatteli, H., et al. (2006). Surface and aerodynamic roughness in arid and semiarid areas and their relation to radar backscatter coefficient. Journal of Geophysical Research 111, F03017.https://doi.org/10.1029/2006JF000462 
Martin, R.L., \& Kok, J.F. (2018). Distinct thresholds for the initiation and cessation of Aeolian saltation from field measurements. Journal of Geophysical Research: Earth Surface 123, 1546-1565. https://doi.org/10.1029/2017JFo04416

Michalsky, J.J., \& Hodges, G.B. (2013). Field measured spectral albedo-four years of data from the western U.S. prairie. Journal of Geophysical Research: Atmospheres 118, 813-825.

Nield, J.M., King, J., Wiggs, G.F.S., Leyland, J., Bryant, R.G., Chiverrell, R.C., etal. (2013). Estimating aerodynamic roughness over complex surface terrain. Journal of Geophysical Research: Atmospheres 118(23), 12-948.

Okin, G.S. (2008). A new model of wind erosion in the presence of vegetation. Journal of Geophysical Research 113, Fo2S10. https://doi.org/10.1029/2007JFo00758

Raupach, M.R. (1992). Drag and drag partitioning on rough surfaces. Boundary-Layer Meteorology 6o, 375-395.

Raupach, M.R., Gillette, D.A., \& Leys, J.F. (1993). The effect of roughness elements on wind erosion threshold. Journal of Geophysical Research: Atmospheres 98(D2), $3023-3029$.

Raupach, M.R., \& Lu, H. (2004). Representation of land-surface processes in aeolian transport models. Environmental Modelling \& Software 19(2), 93-112.

Schaaf, C.B., Feng, G., Strahler, A.H., Wolfgang, L., Li, X., Tsang, T., Strugnell, N.C., Zhang, X., Jin, Y., Muller, J., Philip, L., Barnsley, M., Hobson, P., Disney, M., Roberts, G., Dunderdale, M., Doll, C., D’Entremont, R.P., Hu, B., Lian, S., Privette, J.L., Roy, D. (2002). First operational BRDF, albedo nadir reflectance products from MODIS. Remote Sensing of Environment 83(1-2), 135-148. http://dx.doi.org/10.1016/s0034-4257(02)o0091-3.

Shao, Y., Ishizuka, M., Mikami, M., \& Leys, J.F. (2011). Parameterisation of size-resolved dust emission and validation with measurements. Journal of Geophysical Research: Atmospheres116, Do8203.https://doi.org/10.1029/2010JD014527

Sterk, G., \& Stein, A. (1997). Mapping wind-blown mass transport by modelling variability in space and time. Soil Science Society of America Journal 61(1), 232-239.

Sweeney, M.R., McDonald, E.V., \& Etyemezian,V. (2011).Quantifying dust emissions from desert landforms, eastern Mojave Desert, USA. Geomorphology 135(1-2), 21-34.

Vermote, E., Justice, C., Claverie, M., \& Franch, B. (2016). Preliminary analysis of the performance of the Landsat 8/OLI land surface reflectance product. Remote Sensing of Environment 185, 46-56.

Vest, K.R., Elmore, A.J., Kaste, J.M., Okin, G.S., \& Li, J. (2013). Estimating total horizontal Aeolian flux within shrub-invaded groundwater-dependent meadows using empirical and mechanistic models. Journal of Geophysical Research: Earth Surface 118, 1132-1146. 
Webb, N.P., Okin, G.S., \& Brown, S. (2014a). The effect of roughness elements on wind erosion: The importance of surface shear stress distribution. Journal of Geophysical Research: Atmospheres 119, 6066-6084.

Webb, N.P., Herrick, J.E., \& Duniway, M.C. (2014b). Ecological site-based assessments of wind and water erosion: informing accelerated soil erosion management in rangelands. Ecological Applications 24(6), 1405-1420.

Webb, N.P., Galloza, M.S.,Zobeck, T.M., \& Herrick, J.E. (2016a). Threshold wind velocity dynamics as a driver of aeolian sediment mass flux. Aeolian Research 2O, 45-58.

Webb, N.P., Herrick, J.E., Van Zee, J.W., Courtright, E.M., Hugenholtz, C.H., Zobeck, T.M., et al. (2016b). The National Wind Erosion Research Network: Building a standardized long-term data resource for aeolian research. Modelling and land management. Aeolian Research 22, 23-36.

Webb, N.P., Chappell, A., Edwards, B.L., McCord, S.E., VanZee, J.W., Cooper, B.F., etal. (2019). Reducing sampling uncertainty in aeolian research to improve change detection. Journal of Geophysical Research: Earth Surface 124. https://doi.org/10.1029/2019JFo05042

Webb, N.P., Chappell, A., Legrand, S.L., Ziegler, N.P., \& Edwards, B.L. (2020). A note on the use of drag partition in aeolian transport models. Aeolian Research 42, 100560 .

Weiser, U., Olefs, M., Schoner, W., Weyss, G., \& Hynek, B. (2017). Correction of broadband albedo measurements affected by unknown slope and sensor tilts. AIP Conference Proceedings 1810(1), 090011.

Wiggs, G.F.S., Livingstone, I., Thomas, D.S.G., \& Bullard, J.E. (1996). Airflow and roughness characteristics over partially vegetated linear dunes in the southwest Kalahari Desert. Earth Surface Processes and Landforms 21, 19-34.

Xing, Q., Wu, B., Yan, N., Yu, M., \&Zhu, W. (2018). Sensitivity of BRDF, NDVI, and wind speed to the aerodynamic roughness length over sparse Tamarix in the downstream Heihe River Basin. Remote Sensing 10(1), 56.

Zobeck, T.M., Sterk, G., Funk, R., Rajot, J.L., Stout, J.E., \& Van Pelt, R.S. (2003). Measurement and data analysis methods for field-scale wind erosion studies and model validation. Earth Surface Processes and Landforms: The Journal of the British Geomorphological Research Group 28(11), 1163-1188. 


\section{Acknowledgements}

Data from the National Wind Erosion Network can be accessed at the network data portal: winderosionnetwork.org/data-portal/public-data. To access the Jornada NWERN data, scroll to the "Jornada Experimental Range NM (LTAR)" dataset and click on "2018". The data from the JER sites can be accessed via Zenodo at DOI 10.5281/zenodo.3542293. Funding support for this research was provided to NPZ and SLLeG by the U.S. Army Engineer Research and Development Center (ERDC) Basic Research Program (FWIC: 2469K1/FAN: U4357455 and FWIC: 71HCD7/FAN: U4362964) sponsored by the Assistant Secretary of the Army for Acquisition, Logistics, and Technology (ASA-ALT), to NPW by the Department of Interior, Bureau of Land Management and to NPW and AC by a joint fund from the US National Science Foundation and UK Natural Environmental Research Council (Award EAR-1853853). This research was a contribution from the Long-Term Agroecosystem Research (LTAR) network. LTAR is supported by the United States Department of Agriculture. We thank Brad Cooper, Justin Van Zee, Ericha Courtright and collaborators across the National Wind Erosion Research Network for maintaining the field sites and data. Any use of trade, product, or firm names is for descriptive purposes only and does not imply endorsement by the U.S. Government. Permission to publish was granted by Director, ERDC Cold Regions Research and Engineering Laboratory. The USDA, New Mexico State University, Cardiff University and the US Army are equal opportunity providers and employers. 


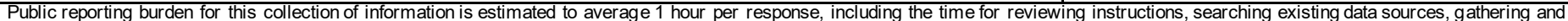

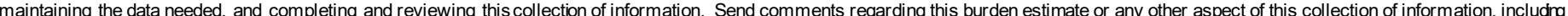

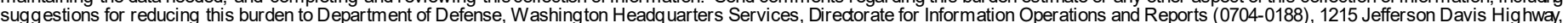

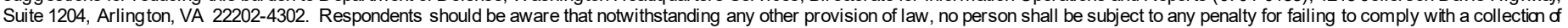
information if it does not display a currently valid OMB control number. PLEASE DO NOT RETURN YOUR FORM TO THE ABOVE ADDRESS.

\begin{tabular}{l|l|l} 
1. REPORT DATE (DD-MM-YYYY) & 2. REPORT TYPE & 3. DATES COVERED (FrOm - To)
\end{tabular} April 2021 Final

4. TITLE AND SUBTITLE 5a. CONTRACT NUMBER

Scale Invariance of Albedo-Based Wind Friction Velocity

5b. GRANT NUMBER

5c. PROGRAM ELEMENT NUMBER

$611102 \mathrm{AB} 200$

6. AUTHOR(S)

5d. PROJECT NUMBER

480351

Nancy P. Ziegler, Nicholas P. Webb, Adrian Chappell, Sandra L. LeGrand

5e. TASK NUMBER

5f. WORK UNIT NUMBER

A1010

7. PERFORMING ORGANIZATION NAME(S) AND ADDRESS(ES)

8. PERFORMING ORGANIZATION REPORT NUMBER

See next page.

ERDC/CRRELMP-21-1

9. SPONSORING / MONITORING AGENCY NAME(S) AND ADDRESS(ES)

10. SPONSOR/MONITOR'S ACRONYM(S)

Headquarters, U.S. Army Corps ofEngineers

Washington, DC 20314-1000

11. SPONSOR/MONITOR'S REPORT NUMBER(S)

\section{DISTRIBUTION / AVAILABILITY STATEMENT}

Approved for public release; distribution is unlimited.

13. SUPPLEMENTARY NOTES

This paper was originally published in the Journal of GeophysicalResearch: Atmospheres on 26 July 2020.

\section{ABSTRACT}

Obtaining reliable estimates of aerodynamic roughness is necessary to interpret and accurately predict aeolian sediment transport dynamics. However, inherent uncertainties in field measurements and models of surfaceaerodynamic properties continue to undermine aeolian research, monitoring, and dustmodeling. A new relation between aerodynamic shelter and land surface shadow has been established at the wind tunnel scale, enabling the potential for estimates of wind erosion and dust emission to be obtained across scales from albedo data. Here, we compare estimates of wind friction velocity $(u *)$ derived from traditional methods (wind speed profiles) with those derived from the albedo model at two separate scales using bare soil patch (via net radiometers) and landscape (via MODIS $500 \mathrm{~m}$ ) datasets. Results show that profile-derived estimates of $u *$ are highly variable in anisotropic surface roughness due to changes in wind direction and fetch. Wind speed profiles poorly estimate soil surface(bed) wind friction velocities necessary for aeolian sediment tran sport research and modeling. Albedo-based estimates of $u *$ at both scales have small variability because the estimate is integrated over a defined, fixed area and resolves thepartition of wind momentumbetween roughness elements and the soil surface. We demonstrate that the wind tunnel-based calibration of albedo for predicting wind friction velocities at the soil surface $\left(u s^{*}\right)$ is applicable across scales. The albedo-based approach enables consistent and reliable drag partition correction across scales for model and field estimates of $u_{s^{*}}$ necessary for wind erosion and dustemission modeling.

\section{SUBJECT TERMS}

Aerodynamic roughness, friction velocity, satellite remote sensing, albedo, aeolian, dust

\begin{tabular}{|c|c|c|c|l|l|}
\hline \multicolumn{2}{|l|}{ 16. SECURITY CLASSIFICATION OF: } & $\begin{array}{c}\text { 17. LIMITATION } \\
\text { OF ABSTRACT }\end{array}$ & $\begin{array}{l}\text { 18. NUMBER } \\
\text { OF PAGES }\end{array}$ & $\begin{array}{l}\text { 19a. NAME OF RESPONSIBLE } \\
\text { PERSON }\end{array}$ \\
\cline { 1 - 2 } $\begin{array}{c}\text { a. REPORT } \\
\text { Uncla ssified }\end{array}$ & $\begin{array}{c}\text { b. ABSTRACT } \\
\text { Unclassified }\end{array}$ & $\begin{array}{c}\text { c. THIS PAGE } \\
\text { Unclassified }\end{array}$ & SAR & 34 & $\begin{array}{l}\text { 19b. TELPHONE NUMBER (include } \\
\text { areade) }\end{array}$ \\
\end{tabular}


PERFORMING ORGANIZATION NAME(S) AND ADDRESS(ES)

U.S. Army Engineer Research and Development Center Cold Regions Research and Engineering Laboratory,

72 Lyme Road, Hanover, NH 03755

USDA-ARS

Jornada Experimental Range

Las Cruces, NM 88003

School of Earth and Ocean Sciences

Cardiff University

Cardiff CF10 3XQ, UK 